\title{
Cellular localization of the heat shock transcription factors HSF1 and HSF2 in the rat brain during postnatal development and following hyperthermia
}

\author{
Ian R. Brown *, Sheila J. Rush \\ Department of Zoology, University of Toronto at Scarborough, 1265 Military Trail, West Hill, Toronto, Ontario, Canada M1C 1A4
}

Accepted 22 December 1998

\begin{abstract}
The heat shock transcription factor HSF1 mediates the induction of heat shock genes in response to temperature elevation and other traumatic events. The induced hsps play roles in cellular repair and protective mechanisms. Immunocytochemistry revealed that in the unstressed rat, HSF1 was already prepositioned in the nucleus at abundant levels in both neuronal and glial cell types. Following a fever-like temperature, glial cells rapidly induced hsp70 whereas populations of large neurons did not. The lack of hsp70 induction in these neurons in vivo did not appear to be due to deficiencies in levels of nuclear HSF1. During postnatal development of the cerebellum, levels of HSF1 increased progressively from day 1 to 30. Members of the hsp gene set are also constitutively expressed in the unstressed animal and play roles as molecular chaperones. HSF2, which has been proposed as a developmental regulator of constitutive heat shock gene expression, demonstrated a developmental alteration in cellular localization, namely a nuclear distribution in neurons at postnatal day 2 and a cytoplasmic localization at day 30. During postnatal development the overall levels of neural HSF2 declined. This profile showed no obvious correlation with previously observed levels of constitutive hsp expression during postnatal neural development. (C) 1999 Elsevier Science B.V. All rights reserved.
\end{abstract}

Keywords: Heat shock protein; Hsp70; Stress response

\section{Introduction}

In response to a range of stressful stimuli, cells activate the highly conserved heat shock (stress) response in which ongoing gene expression is repressed and a set of genes encoding heat shock proteins (hsps) is induced [22,34]. Hsps play important roles in repair of cellular damage and in protection of cells from subsequent stress [14,19,34,38]. The heat shock response has been widely studied in cells grown on tissue culture however, analysis of the in vivo response, particularly in the nervous system, is increasing [8,31]. Many hsps are also expressed constitutively in the unstressed cell where they play vital roles as molecular chaperones $[3,14,15,18]$.

Heat shock transcription factors (HSF) regulate the stress response at the transcription level by binding to a highly conserved heat shock element (HSE) which is present in the promoter region of heat shock genes [33,53]. In mammalian cells, HSF1 mediates the induction of heat shock genes in response to temperature elevation and other

\footnotetext{
* Corresponding author. Fax: +1-416-287-7642; E-mail: ibrown@scar.utoronto.ca
}

stresses whereas HSF2 is refractory to stressful stimuli $[2,21,35,41,42,45,46,48-50]$. HSF1 is constitutively expressed and converts from a monomer to a DNA-binding trimer in response to stress. HSF2 has been reported to be activated during hemin-induced differentiation of erythroleukemia cells $[49,50]$ and may play a role as a potential developmental regulator of heat shock gene expression during embryogenesis and spermatogenesis [23,32,44,47].

In previous studies, we have reported a differential induction of hsp70 in various cell types in the mammalian brain in response to a physiologically relevant increase in body temperature $[5,6,8]$. For example, glial cells in the adult brain, particularly oligodendrocytes, show a rapid induction of hsp70 mRNA and protein whereas several populations of large neurons, which exhibit high levels of constitutive hsp70 and hsp90, do not $[12,13,24-26,39$, 40,51]. During postnatal development of the brain, we have noted changes in the abundance levels of constitutively expressed heat shock proteins such as hsp90 and hsp60 [9].

Given the differential induction of hsp70 in cell types in the hyperthermic mammalian brain and developmental changes in constitutive hsp expression, the present study 


\section{$\mathrm{Cb}$}

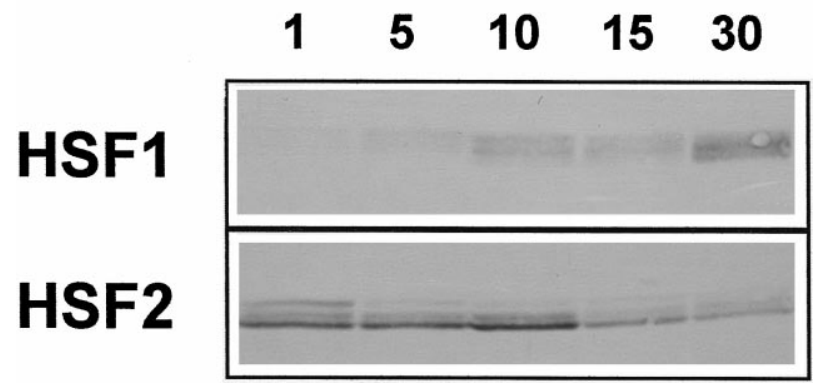

Fig. 1. Western blot analysis of HSF1 and HSF2 protein levels during postnatal development of the rat cerebellum. Aliquots (100 ug protein) of cerebellar tissue extract obtained from animals at the indicated postnatal ages (1 to 30 days) were subjected to Western blot analysis with a 1:50,000 dilution of HSF1 and HSF2 antibody. Proteins of approximate molecular weight $70 \mathrm{kDa}$ were detected. Levels of HSF1 protein were observed to increase during postnatal cerebellar development while levels of HSF2 showed a developmental decrease. $\mathrm{Cb}$, cerebellum.

was undertaken to investigate the in vivo localization in a range of neuronal and glial cell types of the heat shock transcription factors HSF1 and HSF2 during postnatal development and following hyperthermia. In addition, the abundance levels of HSF1 and HSF2 were examined during postnatal neural development.

\section{Materials and methods}

\subsection{Induction of hyperthermia}

Body temperature of male Wistar rats was elevated by $2.8 \pm 0.3^{\circ} \mathrm{C}$ above normal body temperature $\left(37.8 \pm 0.2^{\circ} \mathrm{C}\right)$ by placement of animals in a dry incubator preheated to $42^{\circ} \mathrm{C}$. Body temperature was monitored by a rectal thermistor probe. Maximum rectal temperature was reached 40 min after placement in the incubator. Rats were maintained at the increased body temperature of plus $2.8 \pm 0.3^{\circ} \mathrm{C}$ for 1 h. In other cases, animals were allowed to recover for $4 \mathrm{~h}$ at room temperature after $1 \mathrm{~h}$ of elevated body temperature.

\subsection{Western blot analysis}

Tissue samples from Wistar rats at the indicated developmental ages were prepared for Western blot analysis as previously described using 'buffer $C^{\prime}$ ' containing protease inhibitors [7]. For the determination of protein levels of the transcription factors HSF1 and HSF2, tissue extracts (100 ug protein) were subjected to ECL Western blot analysis [7] using primary antibody dilutions of 1:50,000. The two antibodies, which were donated by Kevin Sarge (University of Kentucky) and Richard Morimoto (Northwestern University), have previously been shown to be highly specific in discriminating mammalian HSF1 and HSF2 $[46,47]$. Data representative of developmental analyses on four sets of animals are shown. Western blot analysis of residual centrifugation pellets demonstrated that variation in extraction efficiency of HSF1 and HSF2 at the various developmental ages did not occur.

\subsection{Immunocytochemistry}

Brain tissue was prepared following intracardial perfusion with $4 \%$ paraformaldehyde and frozen sections cut on a cryostat at 20 um as previously described $[25,26]$. Tissue sections were rehydrated in $0.1 \mathrm{M}$ phosphate buffer saline pH 7.4, 0.2\% Triton X-100, 1.0\% BSA (PBS-G) for 20 min at room temperature, blocked for $2 \mathrm{~h}$ at room temperature in PBS-G plus 5\% normal goat serum. Sections were incubated at room temperature for $18 \mathrm{~h}$ in primary antibody diluted at 1:3000 for the HSF1 and HSF2 antibodies and 1:15,000 for the hsp70 antibody (code \#971 from Robert Tanguay, Laval University). We have previously demonstrated by two dimensional Western blotting that the 971 antibody is specific to the stress-inducible form of rat hsp70 and does not react to rat hsc70 [27]. Sections were washed twice for $5 \mathrm{~min}$ in PBS-G and incubated for $2 \mathrm{~h}$ at room temperature in goat anti-rabbit $\operatorname{IgG}$ (from Vector Lab) diluted 1:400 in PBS-G plus 5\% normal goat serum, washed twice for $5 \mathrm{~min}$ in PBS-G, incubated in 3\% peroxidase at room temperature for $30 \mathrm{~min}$, washed twice for $10 \mathrm{~min}$ in PBS-G and processed with the Vectastain Elite $\mathrm{ABC}$ kit for $1 \mathrm{~h}$ at room temperature followed by two washes in PBS-G. Diaminobenzidine (DAB kit) was used as the chromogen. No signal was observed when either the primary or secondary antibodies were omitted. Immunocytochemical data representative of three sets of animals are shown.

\section{Results}

\subsection{Changes in levels of HSF1 and HSF2 during postnatal neural development}

Western blots revealed pronounced changes in levels of the heat shock transcription factors HSF1 and HSF2 during

Fig. 2. Intracellular localization of HSF1 and HSF2 in the unstressed and hyperthermic rat brain at postnatal day 30 . Tissue sections from brain regions of control animals (postnatal day 30) were immunostained with a 1:3000 dilution of either the HSF1 antibody (A-C) or the HSF2 antibody (D-F). (A) Cerebellum showing in vivo localization of HSF1 to the nucleus of Purkinje neurons (PN) and granule neurons (GN) in the unstressed rat brain. (B) Brainstem neurons showing nuclear localization of HSF1 (arrow). (C) Oligodendrocytes in the brainstem demonstrating a nuclear HSF1 signal (arrow). Inserts in Panels B and C indicate that the nuclear localization of HSF1 is retained in $1 \mathrm{~h}$ hyperthermic animals in neurons (B) and in oligodendrocytes (C) of the brainstem. Panels D to F-Cytoplasmic localization of HSF2 in the cell body (arrows) and dendritic processes (arrowheads) of Purkinje neurons in the cerebellum (D), brainstem neurons (E) and neurons in the cerebral cortex (F). Bar, 25 um. 
postnatal development of rat brain. As shown in Fig. 1, a developmental increase in HSF1 was noted in the cerebel- lum from postnatal day 1 to day 30 (young adult). Other brain regions such as the cerebral cortex showed a similar
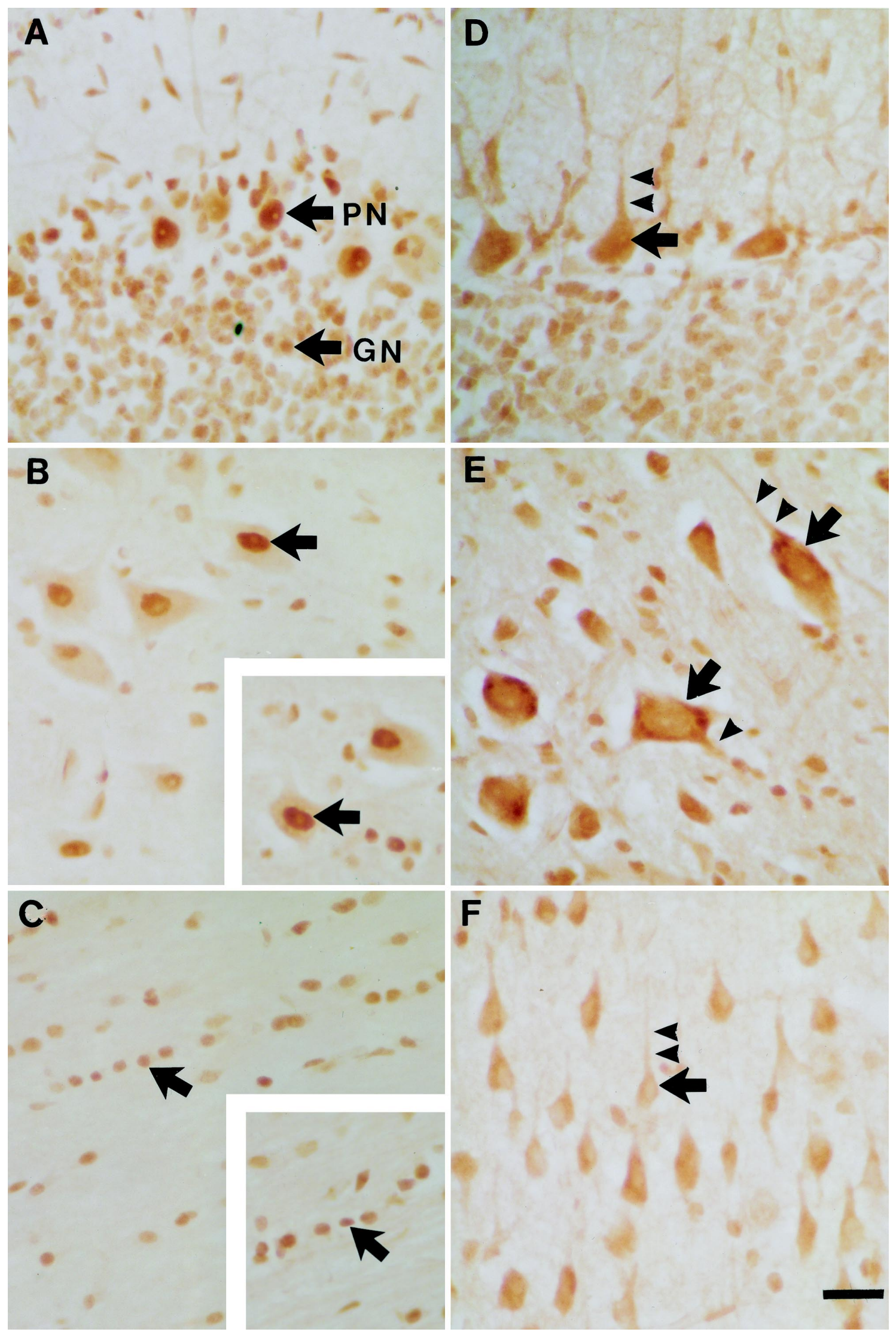
developmental increase in this transcription factor; however, the cortical HSF1 level was lower than that observed for cerebellum (data not shown). As previously reported, the cerebellum contains the highest level of HSF1 in

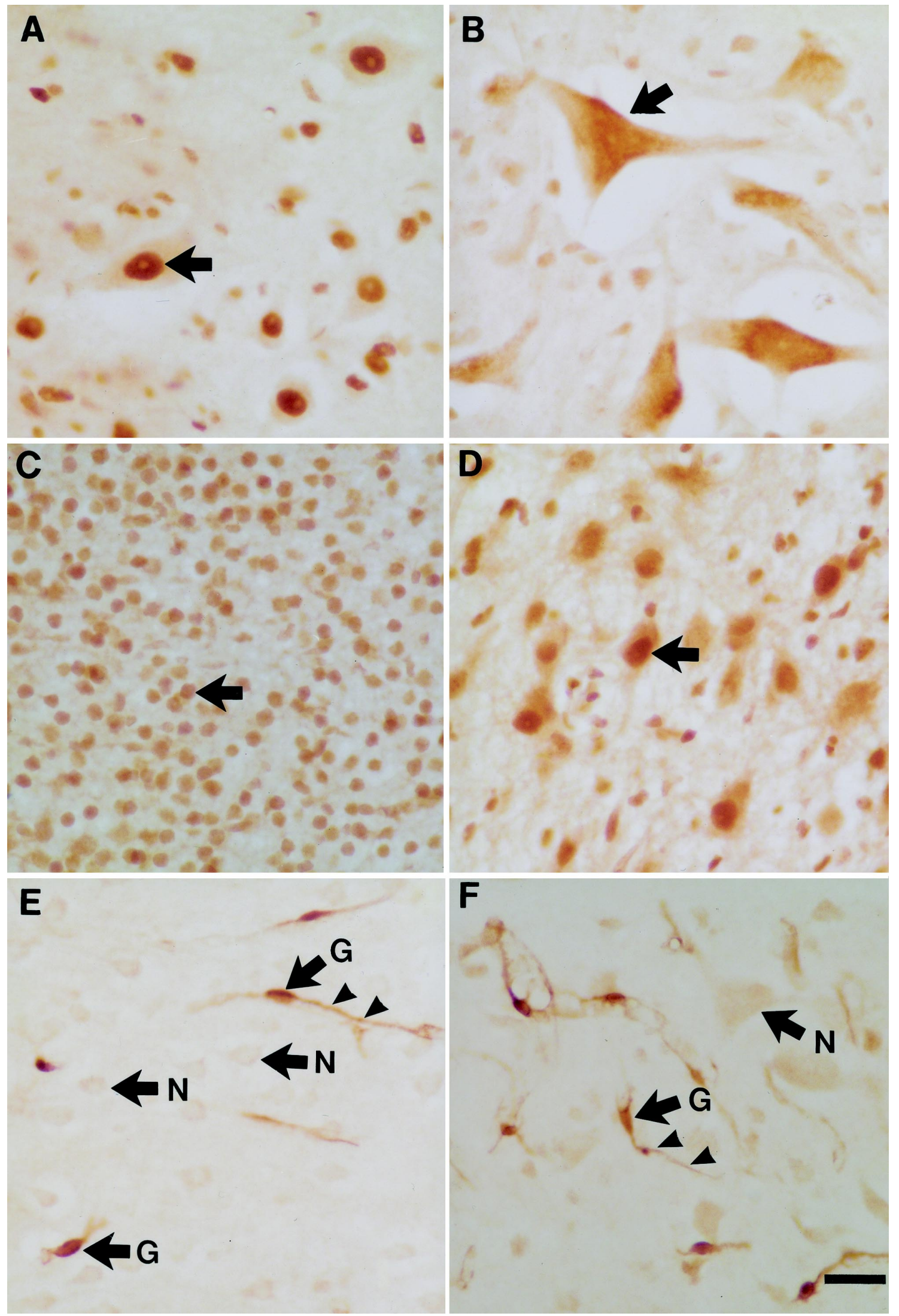


regions of the adult brain [7]. Two isoforms of HSF1 protein were detected which likely arise from alternative splicing of HSF1 pre-mRNA [16].

HSF2 may play a role as a potential developmental regulator on heat shock gene expression $[23,44]$. In contrast to the increase which was noted for HSF1, HSF2 demonstrated a developmental decline in abundance levels during postnatal development of the cerebellum from day 1 to day 30 (Fig. 1). Isoforms of HSF2 were apparent which were likely generated by alternative splicing of HSF2 pre-mRNA [11,17]. The lowest molecular weight isoform may correspond to the beta HSF2 form which has been reported to be a less potent transcriptional activator [17].

\subsection{Immunological localization of HSF1 in neuronal and glial cells of the control and hyperthermic rat brain}

Immunocytochemistry was employed to determine the in vivo localization of HSF1 in neural cell types in the control and hyperthermic rat. In unstressed animals at postnatal day $30, \mathrm{HSF} 1$ was already prepositioned in the nucleus of a range of neuronal and glial cell types. Purkinje neurons (PN) and granule neurons (GN) in the cerebellum (Fig. 2A) and brainstem neurons and oligodendrocytes (Fig. 2B,C) demonstrated a strong nuclear localization of HSF1 in control animals. In brainstem neurons, some HSF1 reactivity was apparent in the cytoplasm (Fig. 2B). The nuclear pattern of HSF1 localization in neuronal and glial cells was also observed at earlier postnatal neural stages which were examined (postnatal days 2 and 11data not shown). Following a physiologically relevant elevation of body temperature of $2.8 \pm 0.3^{\circ} \mathrm{C}$, the nuclear pattern of HSF1 localization was retained in both neuronal and glial cell types in vivo (shown as inserts in Fig. 2B,C).

\subsection{Intracellular localization of HSF2 in the rat brain}

In the rat brain at postnatal day $30, \mathrm{HSF} 2$ showed a prominent cytoplasmic localization in Purkinje neurons in the cerebellum (Fig. 2D) and in neurons of the brainstem and cerebral cortex (Fig. 2E,F). Both the neuronal cell body (arrows) and dendritic processes (arrowheads) were positive for HSF2. Following a fever-like temperature shock of $2.8 \pm 0.3^{\circ} \mathrm{C}$, the cytoplasmic localization of HSF2 was retained (data identical to Fig. 2D-F). Fig. 3 compares the nuclear localization of HSF1 at postnatal day 30 in brainstem neurons (panel A) to the cytoplasmic distribu- tion of HSF2 in the cell body and dendritic processes of this class of neuron (panel B). In contrast to this cytoplasmic localization of HSF2 in the young adult brain at postnatal day 30, a nuclear localization was apparent at postnatal day 2 in cortical and brainstem neurons in unstressed animals (Fig. 3C,D). The difference between the nuclear localization of HSF2 in cortical and brain stem neurons at postnatal day 2 (Fig. 3C,D) and the cytoplasmic distribution of HSF2 in the cell body and dendritic processes of cortical and brain stem neurons in the young adult (Figs. 2 and 3B) was striking.

\subsection{Effect of body temperature on neural hsp70 induction}

Immunocytochemistry with an anti-hsp70 antibody demonstrated that a fever-like temperature increase of $2.8 \pm 0.3^{\circ} \mathrm{C}$ induced hsp70 in glial cells $(\mathrm{G})$ in both the cerebral cortex and brain stem of the young adult but not in neighbouring neurons (N) (Fig. 3E,F) even though these neurons exhibited abundant levels of nuclear HSF1. The lack of hsp70 induction in populations of large neurons in response to a fever-like temperature shock does not appear to be due to deficiencies in HSF1. The high endogenous level of hsc70 in these neuronal cell populations, which we have previously reported, may dampen hsp70 induction [25-27]. In response to more severe stress such as ischemia, these neurons can induce hsp70 [37]. The induced hsp70 in the glial cells in the cerebral cortex and brain stem was localized to the cell body (arrows) and to glial cellular processes (arrowheads) (Fig. 3E,F).

\section{Discussion}

Our previous studies and those of others, in both in vivo and in vitro mammalian neural systems, have reported that glial cells rapidly induce hsp70 in response to physiologically relevant temperature shock whereas several neuronal populations do not $[6,8,10,12]$. The heat shock transcription factor HSF1 mediates stress induction of hsp genes by converting from a monomeric form to a DNA-binding trimeric form which complexes with specific heat shock elements (HSE) in the promoter region of hsp genes $[33,53]$. The present study was undertaken to examine HSF1 distribution in vivo in a range of neuronal and glial cells in the rat brain using immunocytochemistry. Despite the lack of hsp70 induction in populations of large neurons and the presence of this response in adjacent glial cells,

Fig. 3. Developmental changes in HSF2 localization. (A) and (B)-Comparison of the nuclear localization of HSF1 (A) and the cytoplasmic localization of HSF2 (B) in brain stem neurons of the young adult rat (postnatal day 30). (C) and (D) - Nuclear localization of HSF2 at postnatal day 2 in cortical neurons and brain stem neurons respectively. (E) and (F) - Induction of hsp70 protein in glial cells (G) in the cerebral cortex and brain stem (respectively) of the young adult rat following elevation of body temperature for $1 \mathrm{~h}$ and $4 \mathrm{~h}$ recovery at room temperature. Adjacent neuron $(\mathrm{N})$ were immunonegative for hsp70. Arrow (G) — glial cell body. Arrowheads_glial cellular processes. Bar, 25 um. 
abundant levels of HSF1 were detected in both neuronal and glial cells. As expected, HSF1 was localized to the nucleus of glial cells in hyperthermic animals since these cells show a robust induction of hsp70. The interesting observations are that HSF1 is already prepositioned in the nucleus of glial cells in the unstressed animal and that HSF1 is also present in the nucleus of neuronal cells in both control and hyperthermic animals. Previous studies on the cellular localization of HSF1 have focused primarily on tissue culture systems. In cultured Drosophila and Xenopus cells, HSF1 has been localized to the nucleus in control cells [30,52]. However, other studies in cultured Drosophila cells have reported a cytoplasmic localization [54]. Recently a nuclear localization of HSF1 has been observed both in vitro in cultured rat cortical astrocytes and neurons [36] and in vivo in spermatocytes and spermatids [1].

The present results suggest that it is unlikely that the absence of a rapid hsp70 induction response in populations of large neurons in vivo is associated with deficiencies in HSF1 levels or nuclear localization. In primary cultures of hippocampal neurons, the absence of hsp70 induction in response to heat shock has been associated with a lack of HSF1 [28]; however, this HSF1 deficit appears to be a feature of this in vitro system as hippocampal neurons can induce hsp70 in vivo in response to severe stress such as ischemia [37]. Our previous in vivo studies have demonstrated that large neurons have high endogenous levels of constitutive hsc70 which may dampen hsp70 induction in response to a fever-like temperature [25-27]. We have suggested that large neurons may be preprotected against mild stress by their endogenous levels of hsc70 and hence avoid negative aspects of the heat shock response such as transient inhibition of ongoing protein synthesis [25].

A pronounced developmental increase in HSF1 was apparent during postnatal neural development. Compared to the young adult (day 30), very low levels of HSF1 are present at postnatal day 1 to 5 however, a robust neural heat shock response is apparent at both ends of this age spectrum [4]. A question which arises is whether HSF1 has additional functions besides its role in stress induction of heat shock genes. Could there be additional targets of HSF1 which are non-hsp genes? Interestingly, recent studies in which the HSF1 gene has been disrupted in the mouse have shown that, in addition to loss of stress inducibility of the hsp gene set, specific defects are apparent in certain organ systems; for example, the null females are infertile [29]. This has led to the suggestion that HSF1 may have pleiotropic functions in mammalian reproduction, development and physiological function [29]. In Drosophila, HSF is required for oogenesis and early larval development in addition to its role in stress induction of hsp genes [20]. The number of chromosomal HSF-binding sites greatly exceeds the number of known heat shock genes (identified as heat shock puff sites) in salivary gland squashes of Drosophila polytene chromosomes, suggesting additional functions for HSF besides classical induction of heat shock genes [52].

In addition to inducibility by a range of stressful stimuli, members of the hsp gene set are constitutively expressed in unstressed cells and play roles as molecular chaperones $[3,14,15,18]$. HSF2 has been proposed as a potential developmental regulator of heat shock gene expression $[23,32,44,47,49,50]$. In contrast to the increase in HSF1 levels which were observed during postnatal cerebellar development, HSF2 showed a developmental decline. At postnatal day 2 during early differentiation of the cerebellum when HSF2 levels were comparatively high, the protein showed a nuclear localization in cortical and brainstem neurons as would be expected if it were acting as a transcription factor in constitutive expression of hsp genes. In the young adult, HSF2 showed a distinctly different cellular localization since a prominent cytoplasmic signal was apparent in both the neuronal cell body and dendritic processes. Interestingly, a recent study on spermatogenesis has reported that HSF2 exhibits a nuclear localization during early stages of differentiation and a cytoplasmic localization at later stages [1].

In a recent study, we have suggested that members of the hsp gene set are differentially regulated during postnatal neural development [9]. For example, while levels of hsp90 decrease in the developing cerebellum, levels of hsp60 show a developmental increase while hsc70 is abundant throughout postnatal development. These profiles of developmental change in constitutive expression of specific neural hsps show no obvious correlation with the pronounced developmental decline in HSF2 levels which were observed in the present study. Similarly, recent work which has investigated sites of constitutive hsp expression during mammalian embryogenesis has shown that members of the hsp gene set are non-coordinated in their regulation and that their expression patterns do not correlate with the level or localization of HSF2 [23,43]. In addition, during spermatogenesis, sites of constitutive hsp expression do not correlate with the pattern of HSF2 expression [1]. These observations together with the present findings on the localization of HSF2 in dendritic processes and the cell body of neurons of the young adult, suggest that, in addition to functioning as a nuclear transcription factor, HSF2 may be involved in other cellular processes.

\section{Acknowledgements}

We thank Kevin Sarge (University of Kentucky) and Richard Morimoto (Northwestern University) for donation of the HSF1 and HSF2 antibodies and Robert Tanguay (Laval University) for the donation of the hsp70 antibody (code \#971). These studies were supported by grants to I.R.B. from the Medical Research Council of Canada. 


\section{References}

[1] T.P. Alastalo, M. Lonnstrom, S. Leppa, K. Kaarniranta, M.P. Huikko, L. Sistonen, M. Parvinen, Stage-specific expression and cellular localization of the heat shock factor 2 isoforms in the rat seminiferous epithelium, Exp. Cell. Res. 240 (1998) 16-27.

[2] R. Baler, G. Dahl, R. Voellmy, Activation of heat shock genes is accompanied by oligomerization, modification and rapid translocation of heat shock transcription factor HSF1, Mol. Cell. Biol. 13 (1993) 2486-2496.

[3] J. Becker, E.A. Craig, Heat shock proteins as molecular chaperones, Eur. J. Biochem. 219 (1994) 11-23.

[4] I.R. Brown, Hyperthemia induces the synthesis of a heat shock protein by polysomes isolated from the fetal and neonatal mammalian brain, J. Neurochem. 40 (1983) 1490-1493.

[5] I.R. Brown, Induction of heat shock (stress) genes in the mammalian brain by hyperthemia and other traumatic events: a current perspective, J. Neurosci. Res. 27 (1990) 247-255.

[6] I.R. Brown, Induction of heat shock genes in the mammalian brain by hyperthermia and tissue injury, in: J. Mayer, I.R. Brown (Eds.), Heat Shock Proteins in the Nervous System, Academic Press, London, 1994, pp. 31-53.

[7] I.R. Brown, S.J. Rush, In vivo activation of neural heat shock transcription factor HSF1 by a physiologically relevant increase in body temperature, J. Neurosci. Res. 44 (1996) 52-57.

[8] I.R. Brown, F.R. Sharp, The cellular stress gene response in brain, in: D.S. Latchman (Ed.), 'Stress Proteins', Handbook of Experimental Pharmacology, Springer, Heidelberg, 136, 1999, pp. 243-263.

[9] S.M. D'Souza, I.R. Brown, Constitutive expression of heat shock proteins hsp90, hsc70, hsp70 and hsp60 in neural and non-neural tissues of the rat during postnatal development, Cell Stress and Chaperones 3 (1998) 188-199.

[10] B.E. Dwyer, R.N. Nishimura, Heat shock proteins and neuroprotection in CNS culture, In: J. Mayer, I.R. Brown (Eds.), Heat Shock Proteins in the Nervous System, Academic Press, London, 1994, pp. $101-121$.

[11] M.T. Fiorenza, T. Farkas, M. Dissing, D. Kolding, V. Zimarino, Complex expression of murine heat shock transcription factors, Nucleic Acids Res. 23 (1995) 467-474.

[12] J.A. Foster, I.R. Brown, Differential induction of heat shock mRNA in oligodendrocytes, microglia and astrocytes following hyperthermia, Mol. Brain Res. 45 (1997) 207-218.

[13] J.A. Foster, S.J. Rush, I.R. Brown, Localization of constitutive and hyperthermia-inducible heat shock mRNAs (hsc70 and hsp70) in the rabbit cerebellum and brainstem by non-radioactive in situ hybridization, J. Neurosci. Res. 41 (1995) 603-612.

[14] C. Georgopoulos, W.J. Welch, Role of the major heat shock proteins as molecular chaperones, Annu. Rev. Cell Biol. 9 (1993) 601-634.

[15] M.J. Gething, J. Sambrook, Protein folding in the cell, Nature 355 (1992) 33-45.

[16] M.L. Goodson, K.D. Sarge, Regulated expression of heat shock factor 1 isoforms with distinct leucine zipper arrays via tissue-dependent alternative splicing, Biochem. Biophys. Res. Commun. 211 (1995) 943-949.

[17] M.L. Goodson, O.K. Park-Sarge, K.D. Sarge, Tissue-dependent expression of heat shock factor 2 isoforms with distinct transcriptional activities, Mol. Cell. Biol. 15 (1995) 5288-5293.

[18] J.P. Hendrick, F. Hartl, Molecular chaperone functions of heat shock proteins, Annu. Rev. Biochem. 62 (1993) 349-384.

[19] L.E. Hightower, T. Li, Structure and function of the mammalian hsp70 family, in: J. Mayer, I.R. Brown (Eds.), Heat Shock Proteins in the Nervous System, Academic Press, London, 1994, pp. 1-30.

[20] P. Jedlicka, M.A. Mortin, C. Wu, Multiple functions of Drosophila heat shock transcription factor in vivo, EMBO J. 16 (1997) 24522462.

[21] P.E. Kroeger, K.D. Sarge, R.I. Morimoto, Mouse heat shock transcription factors 1 and 2 prefer a trimeric binding site but interact differently with the hsp70 heat shock element, Mol. Cell. Biol. 13 (1993) 3370-3383.

[22] S. Lindquist, E.A. Craig, The heat shock proteins, Annu. Rev. Genet. 22 (1988) 631-677.

[23] M.T. Loones, M. Rallu, V. Mezger, M. Morange, Hsp expression and HSF2 in mouse development, Cell. Mol. Life Sci. 53 (1997) $179-190$.

[24] P. Manzerra, I.R. Brown, Expression of heat shock genes (hsp70) in the rabbit spinal cord: localization of constitutive and hyperthermiainducible mRNA species, J. Neurosci. Res. 31 (1992) 606-615.

[25] P. Manzerra, I.R. Brown, The neuronal stress response: nuclear translocation of heat shock proteins as an indicator of hyperthermic stress, Exp. Cell. Res. 229 (1996) 35-47.

[26] P. Manzerra, S.J. Rush, I.R. Brown, Temporal and spatial distribution of heat shock mRNA and protein (hsp70) in the rabbit cerebellum in response to hyperthermia, J. Neurosci. Res. 36 (1993) 480-490.

[27] P. Manzerra, S.J. Rush, I.R. Brown, Tissue-specific differences in heat shock protein hsc70 and hsp70 in the control and hyperthermic rabbit, J. Cell. Physiol. 170 (1997) 130-137.

[28] C.J. Marcuccilli, S.K. Mathur, R.I. Morimoto, R.J. Miller, Regulatory differences in the stress response of hippocampal neurons and glial cells after heat shock, J. Neurosci. 16 (1996) 478-485.

[29] D.R. McMillan, X. Xiao, L. Shao, K. Graves, I.J. Benjamin, Targeted disruption of heat shock transcription factor 1 abolishes thermotolerance and protection against heat inductible apoptosis, J. Biol. Chem. 273 (1998) 7523-7528.

[30] P.A. Mercier, J. Foksa, N. Ovsenek, J.T. Westwood, Xenopus heat shock factor 1 is a nuclear protein before heat stress, J. Biol. Chem. 272 (1997) 14147-14151.

[31] J. Mayer, I.R. Brown, Heat Shock Proteins in the Nervous System, Academic Press, London, 1994, pp. 1-297.

[32] V. Mezger, M. Rallu, R.I. Morimoto, M. Morange, J.P. Renard, Heat shock factor 2 like activity in mouse blastocysts, Dev. Biol. 166 (1994) 819-822.

[33] R.I. Morimoto, Cells in stress: transcriptional activation of heat shock genes, Science 259 (1993) 1409-1410.

[34] R.I. Morimoto, A. Tissieres, C. Georgopoulos, The Biology of Heat Shock Proteins and Molecular Chaperones, Cold Spring Harbor Laboratory Press, 1994, pp. 1-610.

[35] S.P. Murphy, J.J. Gorzowski, K.D. Sarge, B. Phillips, Characterization of constitutive HSF2 DNA-binding activity in mouse embryonal carcinoma cells, Mol. Cell. Biol. 14 (1994) 5307-5317.

[36] R.N. Nishimura, B.E. Dwyer, Evidence from different mechanisms of induction of hsp70i: a comparison of cultured rat cortical neurons with astrocytes, Mol. Brain Res. 36 (1996) 227-239.

[37] T.S. Nowak, S. Suga, N. Saito, The heat shock response and gene expression in brain after ischaemia, in: J. Mayer, I.R. Brown (Eds.), Heat Shock Proteins in the Nervous System, Academic Press, London, 1994, pp. 55-81.

[38] D.A. Parsell, S. Lindquist, The function of heat shock proteins in stress tolerance: degradation and reactivation of damaged protein, Annu. Rev. Genet. 27 (1993) 437-496.

[39] H. Quraishi, I.R. Brown, Expression of heat shock 90 (hsp90) in neural and nonneural tissues of the control and hyperthermic rabbit, Exp. Cell. Res. 219 (1995) 358-363.

[40] H. Quraishi, S.J. Rush, I.R. Brown, Expression of mRNA species encoding heat shock protein 90 (hsp90) in control and hyperthermic rabbit brain, J. Neurosci. Res. 43 (1996) 335-345.

[41] S.K. Radindran, G. Giorgi, J. Clos, C. Wu, Molecular cloning and expression of a human heat shock factor, HSF1, Proc. Natl. Acad. Sci. U.S.A. 88 (1991) 6906-6910.

[42] S.K. Radindran, R.I. Haroun, J. Clos, J. Wisiewski, C. Wu, Regulation of heat shock factor trimer formation: role of a conserved leucine zipper, Science 259 (1993) 230-234.

[43] M. Rallu, M.T. Loones, Y. Lallemand, R.I. Morimoto, M. Morange, V. Mezger, Function and regulation of heat shock factor 2 during 
mouse embryogenesis, Proc. Natl. Acad. Sci. U.S.A. 94 (1997) 2392-2397.

[44] K.D. Sarge, K.E. Cullen, Regulation of hsp expression during rodent spermatogenesis, Cell. Mol. Life Sci. 53 (1997) 191-197.

[45] K.D. Sarge, V. Zimarino, K. Holm, C. Wu, R.I. Morimoto, Cloning and characterization of two mouse heat shock factors with distinct inducible and constitutive DNA-binding ability, Genes Dev. 5 (1991) 1902-1911.

[46] K.D. Sarge, S.P. Murphy, R.I. Morimoto, Activation of heat shock gene transcription by heat shock factor 1 involves oligomerization, acquisition of DNA-binding activity and nuclear localization and can occur in the absence of stress, Mol. Cell. Biol. 13 (1993) 1392-1407.

[47] K.D. Sarge, O.K. Park-Sarge, J.D. Kirby, K.E. Mayo, R.I. Morimoto, Expression of heat shock factor 2 in mouse testis: potential role as a regulator of heat shock protein gene expression during spermatogenesis, Biol. Reprod. 50 (1994) 1334-1343.

[48] T.J. Schuetz, G.J. Gallo, L. Sheldon, P. Tempest, R.E. Kingston, Isolation of a cDNA for HSF2: evidence for two heat shock factor genes in humans, Proc. Natl. Acad. Sci. U.S.A. 88 (1991) 69116915.
[49] L. Sistonen, K.D. Sarge, B. Phillips, K. Abravaya, R.I. Morimoto, Activation of heat shock factor 2 during hemin-induced differentiation of human erythroleukemia cells, Mol. Cell. Biol. 12 (1992) 1404-1411.

[50] L. Sistonen, K.D. Sarge, R.I. Morimoto, Human heat shock factor 1 and 2 are differentially activated and can synergistically induce hsp70 gene transcription, Mol. Cell. Biol. 14 (1994) 2087-2099.

[51] G.K. Sprang, I.R. Brown, Selective induction of heat shock gene in the fibre tracts and cerebellar neurons of the rabbit brain, Mol. Brain Res. 3 (1987) 89-93.

[52] J.T. Westwood, J. Clos, C. Wu, Stress-induced oligomerization and chomosomal relocalization of heat shock factor, Nature 353 (1991) 822-827.

[53] C. Wu, Heat shock transcription factors: structure and regulation, Annu. Rev. Cell. Dev. Biol. 11 (1995) 441-469.

[54] E. Zandi, T.N. Tran, W. Chamberlain, C.S. Parker, Nuclear entry, oligomerization and DNA binding of the Drosophila heat shock transcription factor are regulated by a unique nuclear localization sequence, Genes Dev. 11 (1997) 1299-1314. 